\title{
AUTOMATIC FIRST BREAKS PICKING USING LINEAR MOVEOUT CORRECTION AND COMPLEX SEISMIC TRACES
}

\author{
Wilker Eduardo Souza1 ${ }^{1}$ Rafael Rodrigues Manenti ${ }^{1}$ and Milton J. Porsani1,2
}

\begin{abstract}
Statics correction corresponds to a time-shift which is applied to seismic trace to eliminate reflections misalignment, caused by topography and weathered layer effects. This correction depends on precise first break picking time determination. Obtain first breaks on seismograms can be a arduous task if data were acquired in complex regions and with low signal to noise ratio. Besides, if the wavelet is generated from a vibroseis source, picking process is even harder once wavelet is non-causal with energy lobes around the maximum value of the reflection. In the present paper an automatic method to obtain the first breaks picking is proposed, which use complex seismic trace envelope. Picking is performed on shot-gathers corrected from linear moveout, which makes direct and refracted waves horizontal. The first breaks picking method is automatic, stable and reliable for calculation of statics correction. The method was tested using shot-gathers from different sedimentary basin and acquired with explosive and vibroseis source. Results obtained with synthetic and real data show the proposed method is robust, numerically stable, computationally efficient and easy to apply.
\end{abstract}

Keywords: automatic picking, static correction, seismic reflection.

RESUMO. A correção estática corresponde a um deslocamento em tempo, aplicado ao traço sísmico, para eliminar a variação no tempo das reflexões causada pela variação da topografia e da camada de intemperismo. Essa correção depende da determinação precisa dos tempos das primeiras quebras, processo este denominado de picking. De um modo geral, a primeira quebra está relacionada com as condições próximas a superfície, como o tipo de fonte e a relação sinal/ruído. Tradicionalmente, a determinação do sinal que corresponde à primeira quebra foi realizada através de uma inspeção visual das amplitudes, e os picking feitos manualmente. Além de ser muito demorada, essa estratégia pode levar a escolhas tendenciosas e inconsistentes, pois, depende da subjetividade de cada profissional. Com o desenvolvimento de computadores modernos, foram criados softwares de picking automáticos, ainda assim, todo o procedimento ainda é muito demorado e subjetivo. Nesse contexto, é proposto um método de picking capaz de determinar, de forma automática e confiável as primeiras quebras do sismograma de reflexão para cálculo das correções estáticas. Os resultados obtidos, sobre dados sintéticos e reais, mostram que o método proposto é robusto, computacionalmente eficiente e fácil de aplicar.

Palavras-chave: picking automático, correção estática, sísmica de reflexão.

\footnotetext{
1 Universidade Federal da Bahia, Centro de Pesquisa em Geofísica e Geologia, Instituto de Geociências, Campus Universitário da Federação Salvador, Bahia, Brazil. E-mails: wilkergeo@ @hotmail.com; rrmanenti@gmail.com; porsani@cpgg.ufba.br

${ }^{2}$ National Institute of Science and Technology of Petroleum Geophysics (INCT/CNPq/MCTI).
} 


\section{INTRODUCTION}

Statics correction determination constitutes a fundamental step in land-based seismic data processing. Static error are sufficient to completely modify structural reflectors' shape in subsurface, creating false structures in seismic section (Cunha, 2010). In industrial scale, Seismic Refraction Tomography is the most used method for obtaining static correction, since it uses first breaks in reflection seismograms which don't add any additional cost to data acquisition and represent great information redundancy about low velocity zone (LVZ). This redundancy is exploited in least-squares algorithms (Amorim, 1985), to obtain thickness and velocities of LVZ, used to compute statics correction. Clearly, efficiency of static correction methods, relied on seismic refraction and refraction data, depending on first break picking reliability (Yilmaz, 2001).

In general, first break quality is related to seismograms signal to noise ratio, terrain conditions and signature source type used in acquisition. As consequence, the first break determination can be a very arduous task if data were acquired in complex regions and with low signal to noise ratio. Besides, if the wavelet is generated from a vibroseis source, picking process is even more difficult once wavelet is non-causal with energy lobes around the maximum pick.

Traditionally, time determination corresponding to first break was done by visual inspection of amplitudes and picks were made manually. Depending on seismic data volume and quality, first break picking process can take $20 \%$ to $30 \%$ of total time spent in data processing (Sabbione \& Velis, 2010). Besides being a time consuming way of determining first breaks, this strategy could lead to tendentious and inconsistent choices, due to each professional's subjective choice. With modern computers development, automatic picking software were created, but since it depends on visual inspection, it's in general slow and subjective. Thus, having an objective and consistent method for automatic first break picking is of great value for land seismic data processing.

Throughout decades, many techniques have been proposed for first break picking obtaintion. First attempts were based on adjacent traces cross correlation for searching first break delay time (Peraldi \& Clement, 1972). However, this technique tends to fail when pulse's shape changes, or when bad/killed traces appear on data. Another approach, included in many commercial softwares, is based on seismic signal energy increase (Coppens, 1985). When signal/noise ratio is relatively high, this method showed to be very robust.

Recent methods include algorithms based on neural network. This approach proved to be useful on determining picks for first breaks. Yet, without a good network training, results can demand manual time consuming adjustment, specially with low quality data.

On this paper, a new first breaks picking method is proposed. The method is based on linear moveout correction (LMO), combined with spatial singular value decomposition (SVD) filtering, which is applied on complex seismic trace envelope.

\section{METHODOLOGY}

In proposed methodology, the process is divided into five steps:

(i) discrete Hilbert transform use to generate complex seismic trace and its corresponding envelope;

(ii) perform linear moveout correction (LM0), flattening direct and refracted reflections;

(iii) signal/noise ratio improvement by filtering seismograms using singular value decomposition (SVD) method on spatial sliding window as proposed by Porsani et al. (2009);

(iv) first break picking pick in individual seismic traces, using a predefined shot-gather time gate defined around first break region, based on accumulated energy up to satisfy a specified user parameter; and

(v) apply inverse LMO correction.

\section{Hilbert Transform and Envelope}

Complex seismic trace concept is illustrated in Figure 1, where $x(t)$ is the real seismic trace and $y(t)$ the $x(t)$ Hilbert transform. When traces are summed, the result is the complex seismic trace $z(t)$ (helical curve), being defined by Eq. (1):

$$
z(t)=x(t)+i y(t)
$$

The imaginary part $y(t)$ is also denominated quadrature or conjugate and $z(t)$ can be determined solely in terms of Hilbert transform or by convolution in time domain, using quadrature operator associated to Hilbert transform. "The analytic signal doesn't contain negative frequency components", and it can be obtained from real signal by suppressing negative frequencies (Claerbout, 1976). Those techniques are based on complex trace's amplitude spectrum observation, which vanishes when $\omega<0$ and it is twice the magnitude when $\omega>0$. As phase keeps constant (except when it is not defined for $\omega<0$ ) the complex trace can be estimated by following form (Mojica et al., 2011): (i) real trace Fourier transform; (ii) zeroing negative frequencies amplitudes and doubling positive frequencies amplitudes, and; (iii) Inverse Fourier transform. 


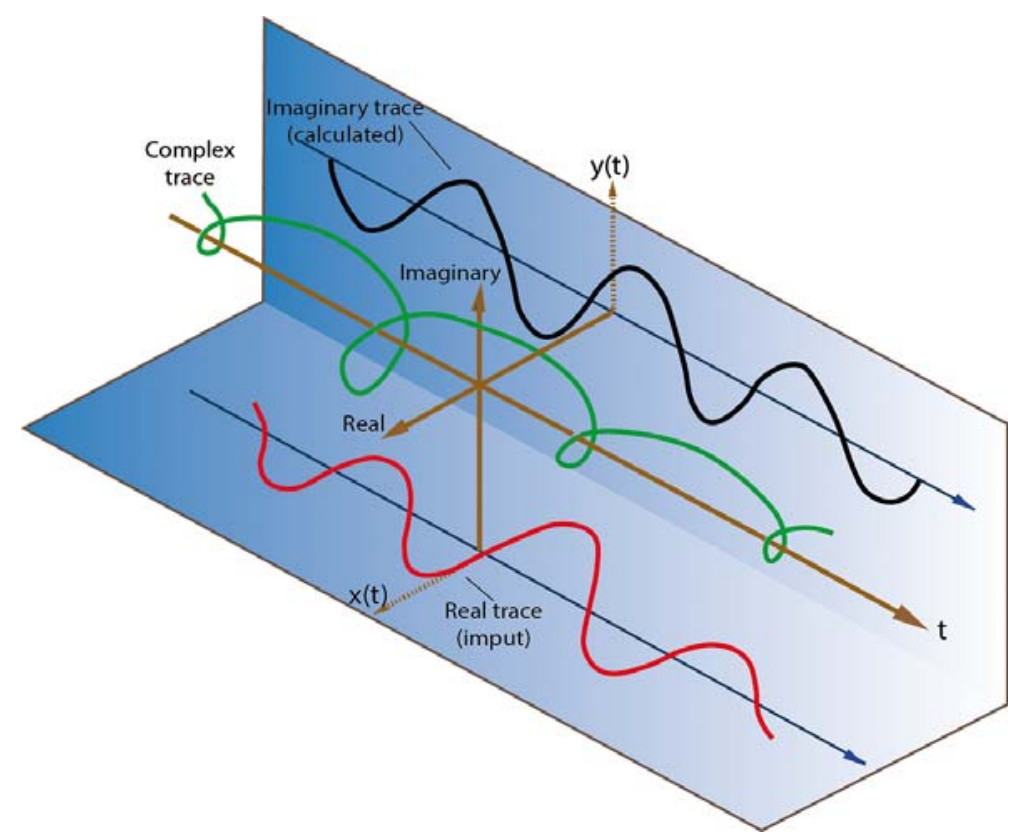

Figure 1 - Complex seismic trace. In black, real part, and in red the imaginary part.

The complex trace $z(t)$ can be visualized as a trace represented in a vector's complex space, which is continually changing its size and rotation, assuming the shape of a helix which shrinks and expands along time axis, as shown in Figure 1. The complex trace concept allows us to define amplitude or envelope, phase, instantaneous frequency and polarity. Those quantities also denominated "attributes" characterize complex trace and those can be plotted the same way as most used for plotting conventional seismic traces.

At any point along complex seismic trace's time axis, the instantaneous amplitude vector $a(t)$ can be calculated, representing amplitude at that point. Mathematically, this amplitude is measured by Eq. (2):

$$
a(t)=\sqrt{x^{2}(t)+y^{2}(t)}
$$

The instantaneous amplitude's calculus illustration associated to complex seismic trace is shown in Figure 2. Figure 2a represents seismic trace $x(t)$ and $2 \mathrm{~b}$ is related to complex seismic trace. The last one consists in a real part $x(t)$ (black) and an imaginary part $y(t)$ (green) calculated by Hilbert transform. Amplitude can be checked in each process step of envelope construction (stars in red and yellow).

The complex seismic trace conversion in a function of instantaneous amplitude is described in Figure 2c, where a function of amplitude is represented graphically as an oscillatory envelope which involves complex trace's both real and imaginary part.
Instantaneous amplitude is a positive function, meaning that its value will always be positive. However, to emphasize that the envelope covers seismic trace's real and imaginary parts, positive and negative portions are represented.

(c)

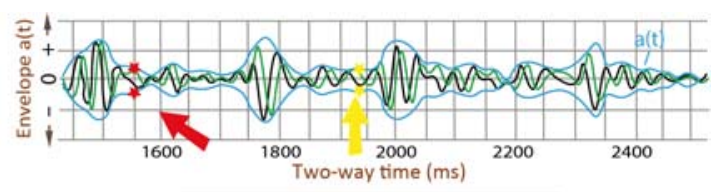

$$
a(t)=\sqrt{x^{2}(t)+y^{2}(t)}
$$

(b)

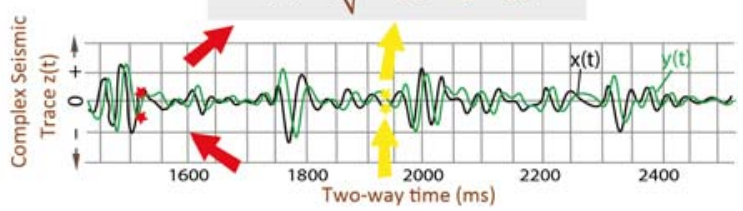

Hilbert Transform

(a)

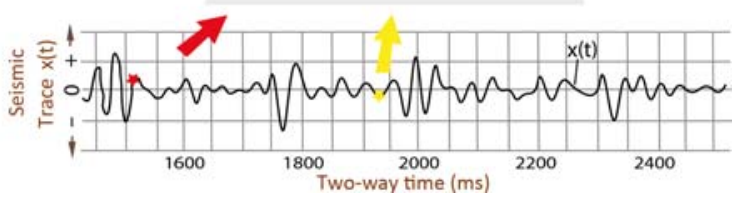

Figure 2 - Complex seismic trace and envelope construction $z(t)$ and $a(t)$, respectively, from seismic trace $x(t)$.

\section{Linear Moveout Correction}

Some seismic event types identified on seismogram have linear characteristics, such as first breaks, which include direct and 
refracted waves. Those events can often be represented as a straight line. The LMO correction is a projection of those events in horizontal axis, eliminating the effect of offset on travel time, removing first break dip on seismograms. For that, in a first step, refraction average velocity is estimated. After defining first refractor's velocity, LMO correction is applied for each record. In each trace's individual correction is based on distance between source and receivers group. Static displacement's calculation process is given by Eq. (3):

$$
t_{L M O}=t_{0}+\frac{X}{V}
$$

where: $t_{L M O}$ is static displacement converted in $m s ; t_{0}$ is the time when source-receiver offset tends to zero; $X$ is offset, which means, distance between source and receivers group; and $V$ is refracted wave velocity.

\section{Spatial SVD filtering}

Following the procedure proposed by Porsani et al. (2009), it was considered a seismic dataset $d\left(t, x_{n}\right)$ where time axis is given in sample number, $t=1,2, \ldots, N_{t}$ and space axis is given in relative space position $x_{n}, n=1,2, \ldots, N_{x}$. Primary reflections have been LMO corrected, being horizontally aligned in $x$-direction. A windowed dataset of $2 M+1$ traces centered at $x_{n}$ is given by a matrix with components $d\left(t, x_{n+j}\right), t=$ $1, \ldots, N_{t}, j=-M, \ldots, 0, \ldots, M$. It can be represented by reduced SVD (Golub \& van Loan, 1996):

$$
d\left(t, x_{n+j}\right)=\sum_{k=1}^{2 M+1} \sigma_{k} u_{k}(t) v_{k}(j)
$$

Here singular values are sorted such $\sigma_{1} \geq \sigma_{2} \geq \ldots \geq$ $\sigma_{2 M+1} \geq 0$. In filtered output dataset, only center traces' first $K$ eigenimages are used. That is, output is

$$
\tilde{d}\left(t, x_{n}\right)=\sum_{k=1}^{K} \sigma_{k} u_{k}(t) v_{k}(0) .
$$

The procedure is started at $n=M+1$ where filtered output is $K$ eigenimages sum corresponding to the $K$ largest singular values of the first $M+1$ traces:

$$
\begin{gathered}
\tilde{d}\left(t, x_{M+1+j}\right)=\sum_{k=1}^{K} \sigma_{k} u_{k}(t) v_{k}(j), \\
j=-M, \ldots, 0 .
\end{gathered}
$$

Then $n$ is increased by one and Eq. (5) is used until $n=$ $N_{x}-M$, where output data is given by $K$ first eigenimages sum of the last $M+1$ traces. That is

$$
\begin{gathered}
\tilde{d}\left(t, x_{N_{x}-M+j}\right)=\sum_{k=1}^{K} \sigma_{k} u_{k}(t) v_{k}(j), \\
j=0, \ldots, M
\end{gathered}
$$

The result is a filtered dataset $\tilde{d}\left(t, x_{n}\right)$ with same dimension as input dataset where energy, which is not coherent in $x$ direction, has been attenuated. Both horizontal events' character and amplitude are well preserved as they are represented by the center trace of the first eigenimages which have the largest energy.

\section{Picks Definition}

The algorithm's last step is pick definition. It was defined for this paper as first break the first strong positive amplitude (black spot), following the SEG data pattern. After obtaining trace's envelope, and applying SVD filter after LMO correction, remains first break definition. This definition is made based on envelope energy, following the next steps:

- Calculate total envelope energy, given Eq. (8), where $N$ is the total sample number and $X_{i}$ is amplitude;

$$
E=\sum_{i=1}^{N} X_{i}
$$

- Tolerance factor $\epsilon$ definition (Eq. 9), which indicates the envelope's total energy percentage $(E)$. In this case, $n$ is the energy percentage, chosen by user, corresponding to sample where pick is defined;

$$
\epsilon=n \cdot E
$$

- Pick's sample definition happens when $\epsilon=n E$. When $\epsilon>n E$, the algorithm will consider the sample before as first break pick.

After pick selection, inverse LMO is applied, using same velocity as used on forward LMO. This process is to place picks to their real position in reflection seismogram.

Due to filtering and pick definition form (a pre-stablished percentage of total energy), the picks won't follow a pattern of choosing always first break maximum amplitude. Instead, picks will be placed in samples around maximum amplitude. Since the most important for first break pick is following a pattern, a last iteration is done.

Using picks table obtained with aforementioned steps, a new window is defined by user with $N / 2$ samples above and $N / 2$ below previous pick. On raw data, the algorithm will search for 


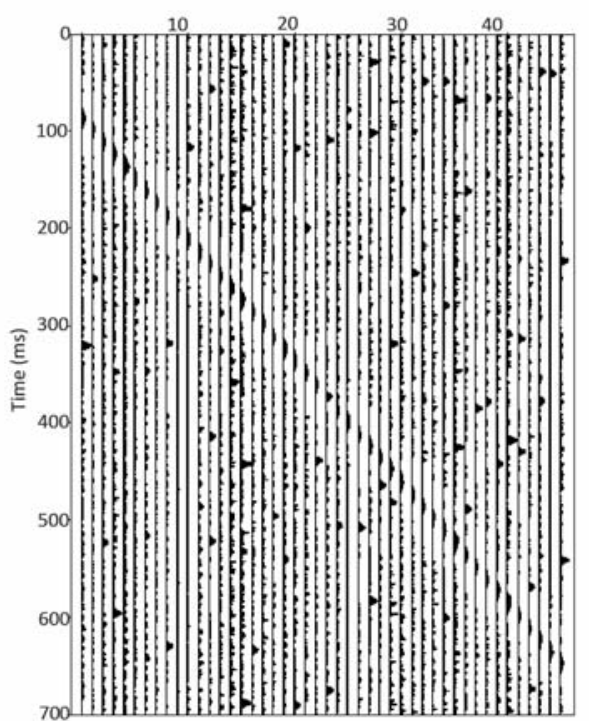

(a)

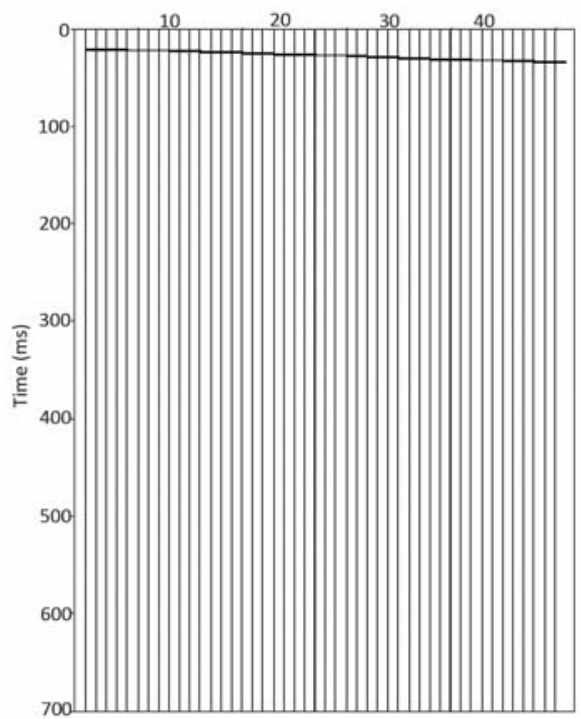

(c)

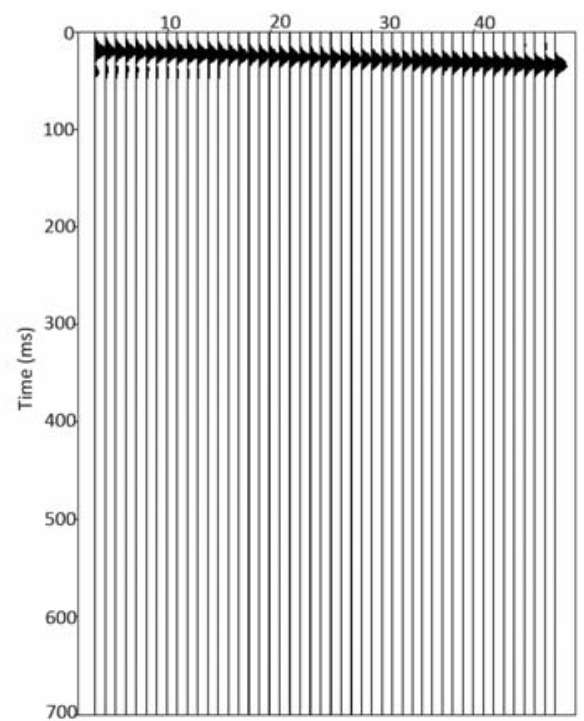

(b)

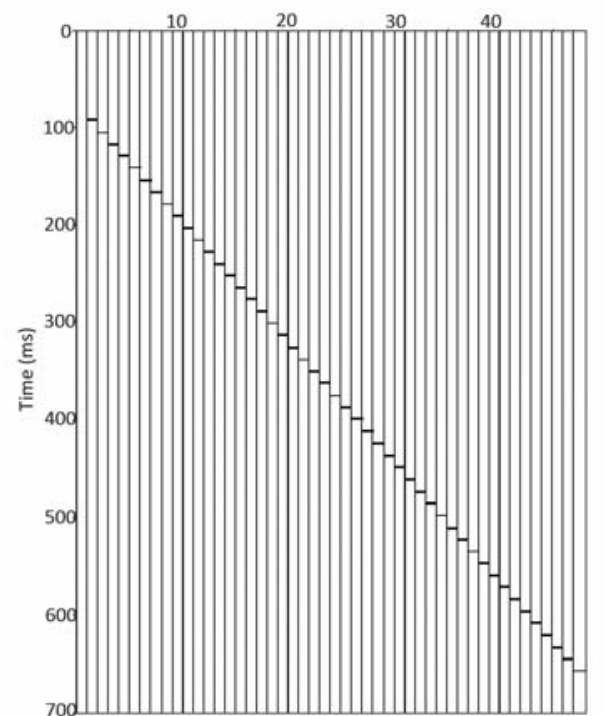

(d)

Figure 3 - Steps of algorithm: (a) envelope; (b) SVD filtering after LMO correction; (c) picks determination; (d) inverse LMO and repositioning of picks on correct samples.

a sample which has the highest amplitude on the window. After placing this sample, the pick is redefined and saved on a txt table and then inserted on each trace header.

To show proposed method's step-by-step, a synthetic data was generated and contaminated with different noise types such as: $60 \mathrm{~Hz}$ noise; random noise, and; high and low frequency spikes. Those kinds of noise were chosen to best simulate a real case scenario. Figure 3 illustrates main proposed automatic first breaks picking method steps. Figure 3a shows a synthetic seis- mogram envelope. Figure $3 \mathrm{~b}$ shows data after LMO correction and SVD filtering. It also has window definition where the method will operate (in this case, 60 first samples in each trace). Figure $3 c$ represents picks definition based on envelopes energy. Figure 3d shows inverse LMO correction result, placing picks in correct sample.

After adding picks trace header, pick visualization static correction steps have all been done on ProMAX SeisSpace software. Figure 4 shows first break picks (red dots) plotted on seismogram. 


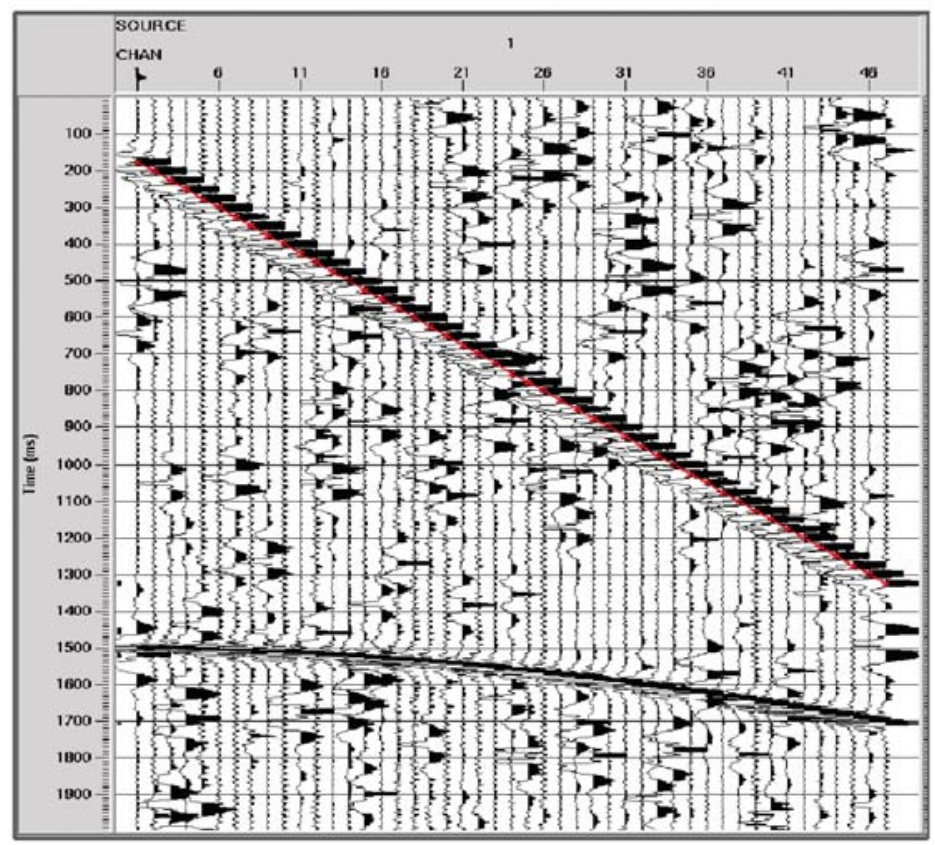

Figure 4 - Synthetic seismogram with first break picks in red dots.

\section{NUMERICAL RESULTS}

Focusing on confirming the proposed method efficiency, this chapter shows applications in real data from different Brazilian sedimentary basins: Recôncavo; São Francisco; Solimões; and Tacutu. Those aforementioned data where all acquired with explosive sources. The method was also tested on a shot-gather obtained using a vibrating source.

Recôncavo basin is located in Bahia State, northeast of Brazil. Figure 5a shows picks plotted on seismogram (red dots). Clearly first break was well defined, even with data contaminated with low frequency noise from acquisition done on rainy weather.

Solimões basin, a intracratonic paleozoic type, is located in Amazon State, north of Brazil. Seismogram is contaminated by noise above first break, which has great amplitudes and all kinds of frequency, impairing the first break definition (Fig. 5b).

Tacutu basin is defined as a mid-sized craton rift, with faults and from mesozoic age, located on center-northeast sector of Roraima State. Seismograms of this area have usually low frequency and high amplitude noise above first arrivals. Figure $5 c$ shows method result on this data.

São Francisco basin is located above São Francisco craton, center of Brazil. For this example a mute was applied to zero all amplitudes above first break. Method results are shown in Figure $5 d$.

Vibroseis shot-gather is the most challenging example, which produces signal that arrive before first break, making pick- ing process harder. Figure 6 illustrates automatic picking results. Although the visual difficulty to define first break, the proposed algorithm proved to be efficient.

\section{CONCLUSIONS}

The automatic first break picking method was applied in landbased Brazilian basins such as Recôncavo, São Francisco, Solimões and Tacutu basins approaching different kinds of noise. Results obtained from proposed method were all satisfactory. In general, it was observed the method is effective for determining first breaks since they are characterized as high energy events. It also had accurate results for vibrating source data. The proposed method is very robust for noisy data and it generates consistent pick tables even in noise presence masking first arrivals and changing wave pulse form. Results with low signal to noise ration were also satisfactory. The method is very efficient and has low computing cost, leaving the user to define only a few parameters obtained after visual inspection.

\section{ACKNOWLEDGEMENTS}

The authors thank FINEP, FAPESB, PETROBRAS, ANP and CNPq (project INCT-GP) for financial support and Paradigm, Landmark to the educational licenses granted to the Centro de Pesquisa em Geofísica e Geologia (CPGG-UFBA). 


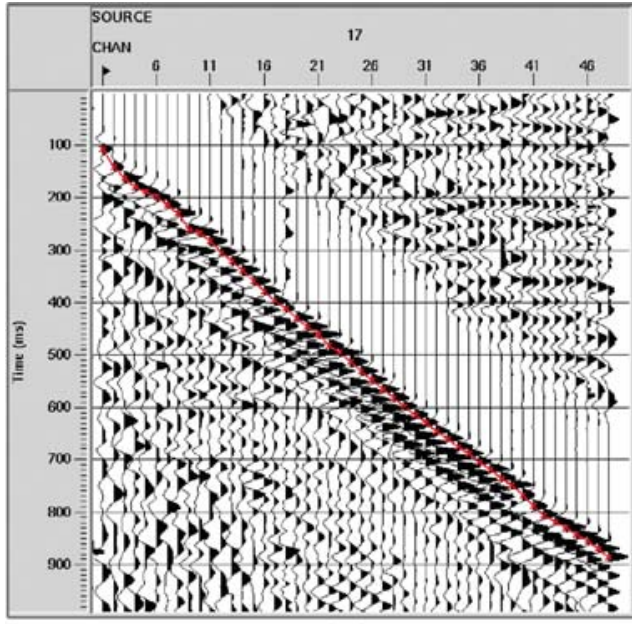

(a)

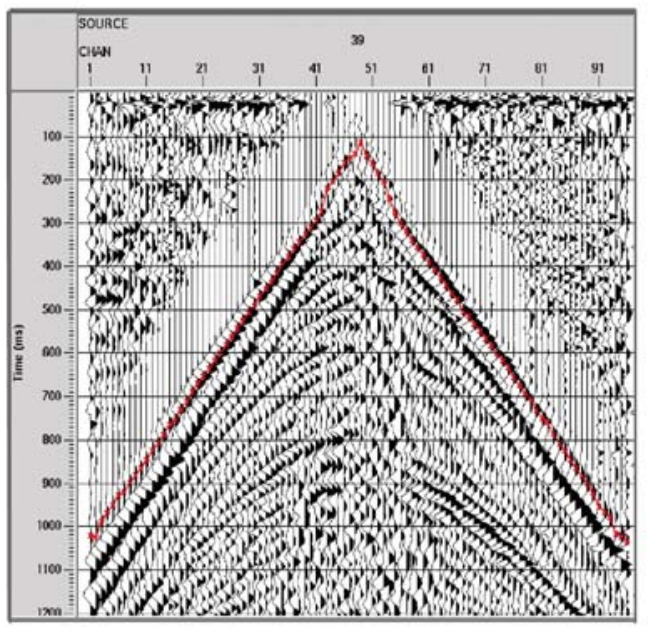

(c)

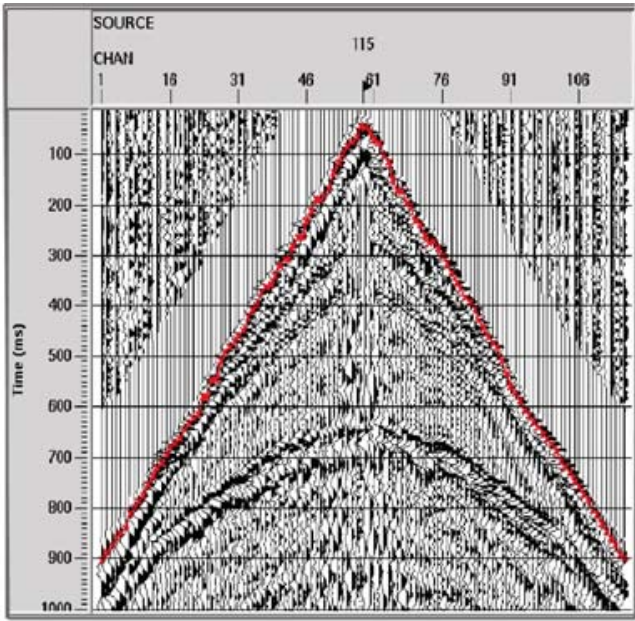

(b)

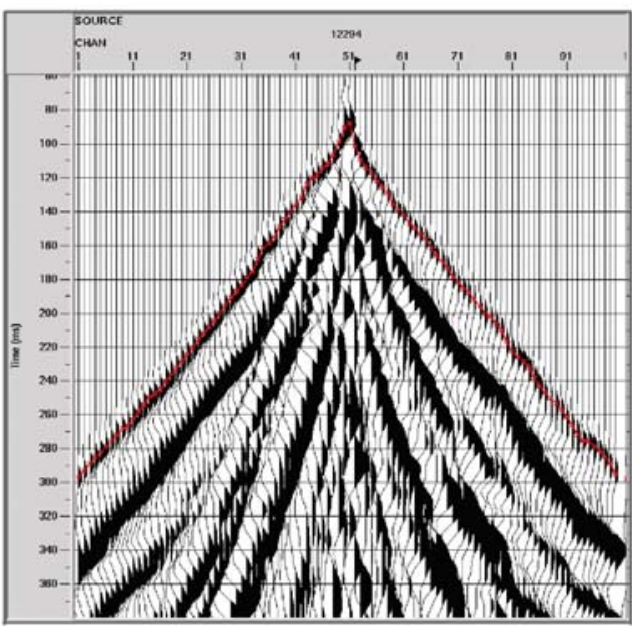

(d)

Figure 5 - Automatic picking in explosive source data: (a) Recôncavo basin; (b) Solimões basin; (c) Tacutu basin; (d) São Francisco basin.

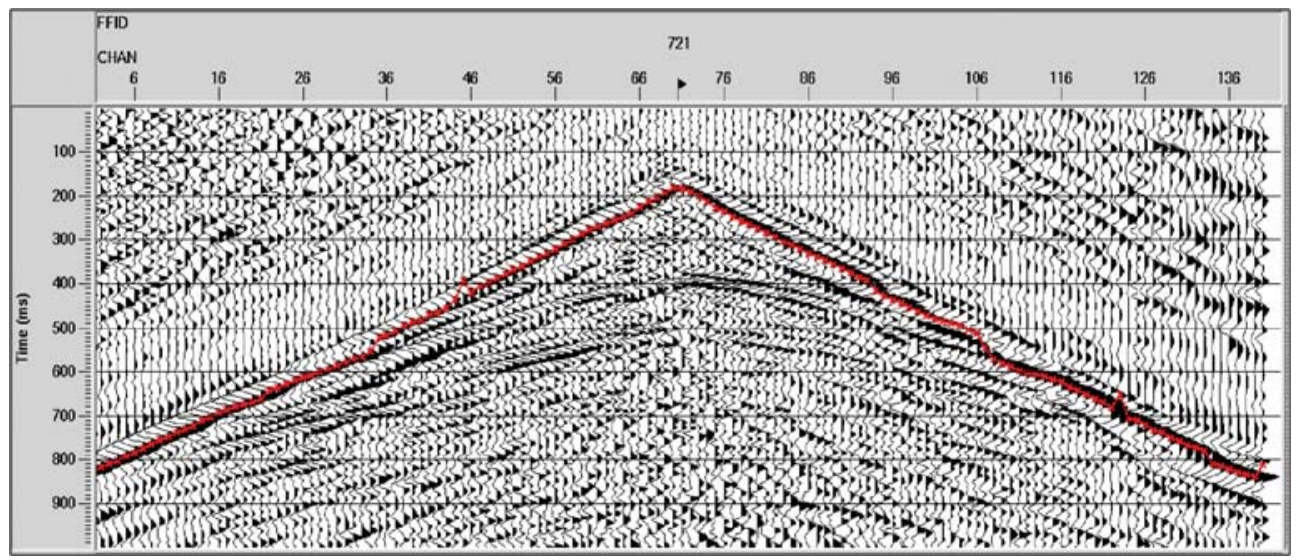

Figure 6 - Seismogram with first break picks in red in vibrating source data from Parnaíba basin. 


\section{REFERENCES}

AMORIM WN. 1985. Cálculo das correções estáticas através do princípio da tomografia sísmica. Doctorate Thesis, Universidade Federal da Bahia, Salvador, Brazil.

CLAERBOUT J. 1976. Fundamentals of geophysical data processing with aplications to petroleum prospecting. Mc Graw-Hill, New York.

COPPENS F. 1985. First arrivals picking on common-offset trace collections for automatic estimation of static corrections. Geophysical Prospecting, 33: 1212-1231.

CUNHA RS. 2010. Cálculo das correções estáticas, Undergraduate Final Project, Universidade Federal da Bahia, Salvador, Brazil.

GOLUB GH \& VAN LOAN CF. 1996. Matrix Computations. 3rd ed., Baltimore: Johns Hopkins University Press, 694 pp.
MOJICA OF, PORSANI MJ \& SILVA MG. 2011. Aplicações da filtragem SVD na análise de velocidades e no empilhamento CMP. In: 12th International Congress of the Brazilian Geophysical Society. Expanded Abstracts. Rio de Janeiro, Brazil. CD-ROM.

PERALDI R \& CLEMENT A. 1972. Digital processing of refraction data: Study of first arrivals. Geophysical Prospecting, 20: 529-548.

PORSANI MJ, SILVA MG, MELO PEM \& URSIN B. 2009. Groundroll attenuation based on SVD Flltering. SEG Expanded Abstracts, 28 : $3381-3385$

SABBIONE JI \& VELIS D. 2010. Automatic first-breaks picking: New strategies and algorithms. Geophysics, 75: 67-76.

YILMAZ 0. 2001. Seismic data analysis: processing, inversion and interpretation of seismic data. SEG. 526 pp.

Recebido em 12 maio, 2016 / Aceito em 1 fevereiro, 2017

Received on May 12, 2016 / Accepted on February 1, 2017 